\title{
An Evaluation of the Universal Accessibility of Bus Stop Environments by Senior Tourists
}

\author{
Manuela P. Rosa ${ }^{1 *}$, Patrícia Costa Pinto², Hugo Assunção ${ }^{3}$ \\ ${ }^{1}$ Research Centre for Tourism, Sustainability and Well-being, University of Algarve, Faro 8005-139, Portugal \\ ${ }^{2}$ Independent Researcher, Almada 2820-557, Portugal \\ ${ }^{3}$ Independent Researcher, Santarém 2000-217, Portugal
}

Corresponding Author Email: mmrosa@ualg.pt

https://doi.org/10.18280/ijsdp.150606

Received: 23 September 2019

Accepted: 5 July 2020

\section{Keywords:}

accessible tourism, bus stop, bus stop environment, people with disabilities, perceptions, senior tourists, sustainable mobility, universal accessibility

\begin{abstract}
Sustainable mobility demands an integrated approach covering all modes of transport in a built environment designed for everyone. Social inclusion strategies required the improvement of transportation for people with reduced mobility. Universal accessibility has been incorporated into urban renovation processes, settlement, housing and transportation. Assessments have been made in measuring the performance of spatial indicators and usually consider technical parameters and/or user perception. In the context of accessible tourism, infrastructures and services have been adapted to be inclusive for all. Accessible built environments are required hence urban spaces, buildings, transport vehicles, information technology \& communication, and services must bear in mind the approach of Age Sensitive Design. The research project Accessibility for All in Tourism focuses on bus stops designed to be age-friendly and inclusive. A questionnaire was developed for the elderly tourist aged 60+ about their perceptions of bus stop environments in their countries. Findings indicate that elderly tourists with disabilities are more critical of the existing accessibility conditions, and have a greater perception of the inclusive characteristics of bus stops. Furthermore, although older people take barrier-free spaces into account, there is some criticism around pedestrian crossings, bench design and the lack of room for wheelchair users.
\end{abstract}

\section{INTRODUCTION}

In order to promote social inclusion and quality of life, to which everyone is entitled, the approach of Universal Design has progressively been incorporated into the public spaces of tourist cities, buildings and transportation vehicles. Universal Design stimulates full participation in community life and tourism activities by ensuring access to the built environment, transport, products and goods, information, public service, education, employment, and health care.

All around the world, national, regional and local governments and institutions are considering universal accessibility an important requirement for the free movement of all people, with emphasis on pedestrian routes. Nowadays, additional attention is being given to the accessibility of transport systems, since these can enhance access to culture places, from a tourist perspective; and from a community perspective, to places of employment, more social participation, respect and social inclusion.

The Research Project "Accessibility for All in Tourism" (ACCES4ALL) focuses on bus stops as an example of modal interfaces, designed according to the approaches of "Universal Design" and "Age Sensitive Design". Its main objective is to develop a pilot study of an accessible, smart and sustainable bus stop to be located at Faro International Airport, in the Algarve, Portugal. A questionnaire was developed for elderly tourists aged 60 or over at the aforementioned airport.

The present paper presents the findings of senior tourists' perceptions of the characteristic of bus stop environments located in their countries. Its main purpose is to understand the specific perceptions of two distinct groups of senior tourists, namely those with and those without disabilities, in relation to bus stop environments whilst taking into account the elements of these facilities and their location.

\subsection{Evaluations of pedestrian built environment}

The approach of Universal Design has been, gradually, assimilated in the political arena, in the social field, academia, industry and the professional field. It has been considered in regulations and technical norms all over the European Union. National, regional and local governments and institutions began to consider universal accessibility an important requirement for the social inclusion of people with disabilities and proceeded with urban renewal to make pedestrian infrastructures more accessible, especially for those using wheelchairs, as well as providing priority parking for persons with disabilities. Nowadays, added attention is being given to the accessibility of interfaces of transport systems, since these can enhance access to activities for people with disabilities and increase social inclusion.

Nevertheless, the evolutionary process of creating barrierfree space within the social and built environment has been difficult and is, possibly, only achievable in the long run. The process of implementation of inclusive urbanism has been challenging and difficult to develop as it involves many participants, requires coordination between all parties, significant funding and quality control. Coordination can be 
difficult as policymakers, stakeholders, architects, engineers and product designers, public and private developers and builders have little understanding about Universal Design.

Universal Design demands a transdisciplinary approach [1]. It requires constant cooperation between professionals of different disciplines, which must be achieved using compatible language. Planning, designing and implementing affordable technical solutions require a full willingness of professionals to act and interact with different entities, participants and users. It needs the flexibility to adjust concepts, objectives and strategies taking into account the different views of agents and users, in this context of human diversity. In these processes, to ensure the usability of spaces, services and products, active participation of the users is essential, as they contribute to the diagnostic of concrete problems, to the consensus of the proposals and the monitoring of performances. Thus, socially constructed knowledge is essential.

Presently a quality control is necessary to ensure that the built environment or performed services adhere to the Universal Design approach through a defined set of quality criteria that meets the requirements of the end-users.

To be adopted entirely in the practical world of planning, designing, and construction, a rigorous and accountable approach must be taken in measuring and analysing the performance of spatial quality in inclusive architecture [2].

The assessment of universal accessibility in the built environment has been conducted by the objective evaluations of experts, through technical parameters taken from regulations, technical norms and guidelines. For instance, some studies presented quantitative methods to assess the universal accessibility of pedestrian networks in an urban environment. Rosa et al. created a methodology for evaluating the universal accessibility of pedestrian infrastructure through the construction of performance indicators. This analysis was achieved through a model of evaluation of the degree of conformity of the spaces of the historic centre of Faro, Portugal, and spatially represented with a Geographical Information System in mind. The analysis confirms the need to trigger processes of urban renovation that must consider universal accessibility [3].

Kockelman et al. [4] developed a research on the evaluation of the usable range of sidewalk cross slopes based on user perception and effort. Ferreira and Sanches propose an accessibility index that considers the current conditions and design characteristics of the infrastructure of sidewalks and street crossings, weighted according to the relative importance of each of the attributes from the respondents' point of view. This provides a classification of the analysed stretch in terms of levels of quality of the services offered [5].

Concerning the assessment of the parameters of bus stop environments, some studies developed methods for measuring accessibility in public transport systems, considering the traditional approach, linked to the proximity between the local community and bus stops (convenience). In these studies, accessibility is perceived broadly as the ability to reach goods, services and destinations, as conceptualized by Littman [6]. However, there is no mention of the conditions of universal accessibility of those systems. The same happens with Corazza et al., that developed a Transit Accessibility Index for Bus Stops, and described the methodology that considers three evaluation categories (transit service, built environment, bus stop quality) and a cluster of seven quantitative indicators (frequency, number of lines, number of inhabitants served, pedestrian catchment area, land use entropy, level of service, level of comfort) qualitatively weighed by transit experts, all regular users [7]. But, later on, they assume that inappropriate design criteria for vehicles, infrastructures, and communications fail to meet users' physical and/or cognitive requirements.

There is an increasing emergence of evaluation methods that consider the actual/potential user needs through questionnaires, interviews, observations, and workshops. These direct methods are characterized by the direct involvement of people and so are consequently based on empirical evidence and allow for indicators of a building's usability towards its users to be established [8].

Some researchers are studying the relationship between bus stop design and users' satisfaction. Physical characteristics of the bus stop such as a bus shelter, seating equipment, signs, and lighting can directly affect user satisfaction.

The accessibility of bus and tram stops in Helsinki was assessed in 2008 when a four-level classification of public transport stops' accessibility was considered: fully accessible, partly accessible, difficult to access, not accessible. Urban parameters were measured (distance between the stop shelter and the roadway; height difference between the pavement and roadway - between 25 and $30 \mathrm{~cm}$ for trams, 16-25 cm for buses), as well as longitudinal gradient (max. 5\%) and lateral gradient (max. 3\%), and in terms of existing equipment (no dangerous items/equipment posing collision danger, warning area near the stop, bench, lights, shelter) [9].

In a recent survey, significant correlations were found between general satisfaction and users' perceptions of the ease of getting on and off buses, the integration of the shelter design with the environment, the adequacy of the shelter for winter and summer usage, the comfort of the shelter, the adequacy of seating, and how well the shelter is maintained. One of the findings of the survey performed on regular users (with a small percentage of 56+ age group) at the Ataköy stop (Istanbul) was that $54 \%$ of the users considered it difficult to access the bus [10].

\section{CASE STUDY: SURVEY OF ELDERLY TOURISTS AT FARO INTERNATIONAL AIRPORT}

\subsection{Research project Accessibility for All in Tourism}

The Research Project "Accessibility for All in Tourism" (ACCES4ALL) focuses on bus stops designed according to the approaches of "Universal Design" and "Age Sensitive Design". It aims to develop a pilot study of an accessible, smart and sustainable bus stop to be located at Faro International Airport, in the Algarve, Portugal.

The universal accessibility of a bus stop cannot be evaluated considering isolated elements. It depends, as previously stated, on the accessibility of the surrounding environment of the bus stop, taking into account sidewalks and pedestrian crossings, elements that are a fundamental part of the network of pedestrian walkways. This network must be coherent and articulated with the existing urban functions in the space.

To be able to assess universal attributes of accessible pedestrian networks, it is necessary to act upon the different constituent elements of these, namely: (a) pedestrian sidewalks (including infrastructures, urban fixtures, traffic signals); pedestrian crossings; and modal interface areas (including bus stops, terminals, reserved parking places for 
people with disabilities).

Accessibility technical features related to the surrounding environment of a bus stop together with the elements of said bus stop were identified in previous research over the last ten years. There is an awareness that an ideal bus stop, for current users, is one that allows visibility and easy access to the bus, is comfortable and convenient, provides clear information, and is safe. ACCES4ALL Project focuses on the senior tourists' points of view.

In the scope of the Project, surveys were carried out on elderly tourists (aged 60 or over) to understand their perceptions about built environments and other issues. In the United Nations reports, generally $60+$ years is considered to refer to the older population [11].

The purpose in this study was to make comparisons across different age groups of older people as well as people with and without disabilities that affect their mobility (motor, visual, hearing and/or orientation problems and others).

Usually, older people as a group are considered in the Universal Design of buildings, public spaces and products. This approach considers the needs of people with functional diversity. The aim is to identify the functional diversity of older people and understand if their perceptions are significantly different according to their functional diversity.

\subsection{Methods}

\subsubsection{Questionnaire development}

The questionnaire aimed to identify the functional diversity of different groups of elderly tourists, and to understand if their mobility, perceptions and digital literacy are significantly different, according to their functional diversity and age. The section of the questionnaire concerning the daily mobility of senior citizens and the perceived criteria of bus stop environments was developed based on previous research by the team and a literature review.

A questionnaire for senior tourists was subsequently developed containing 28 questions filling four pages. These included mainly closed questions eliciting quantitative data and nine open questions offering the opportunity to use their own words generating qualitative response information.

The questions were divided into four categories: information about the respondent, characterization of their daily mobility in their countries and the mobility in the Algarve region (as tourists), information on the perception of universal accessibility conditions in bus stop environments, and their use of communication and information systems and technologies.

The section regarding general information about the respondents contains questions about gender, age group, level of education, professional or employment status, country of residence and nationality, if they live in a city, disability that affects mobility (e.g. motor, visual, hearing and/or orientation problems, other open-questions), the use of technical aids (assistive devices) and factors limiting the use of public transport. The respondents could report the name of the city where they live, the disability that affects their mobility, the use of more than one technical aid and the factors limiting the use of public transport, filling in "other" as issues not listed (open-question).

The section regarding the perception of the conditions for universal accessibility in bus stops in their countries contains questions about the surrounding environment of bus stops and bus stops elements. Questions directly address universal accessibility parameters of this built environment. The scales range from 1 to 4 , where 1 meant "Strongly agree" and 4 meant "Strongly Disagree." A neutral response was avoided. Afterwards, participants were asked the importance of each parameter for their accessibility needs with response alternatives "yes" and "no".

At the beginning of the inquiry, the main goal of the research was revealed and it was specified that the survey was confidential and anonymous, so no names and addresses were asked. At the end, the email of the main researcher of the project was given for people interested in learning about the results of this study.

Concerning the section on perceptions regarding the conditions for universal accessibility of bus stops in their countries, the starting point of the project was to list those technical parameters associated with accessible bus stops, and their surroundings, from the point of view of persons with disabilities, in a context of inclusive mobility. It considers urban aspects, specific pavement and surface materials, information and communication for all and adapted urban fixtures along the surrounding environment of the bus stops and the bus stop itself. Then, perceived criteria were developed to help the evaluation of bus stop environments in a way that is understandable to senior citizens.

\subsubsection{Data collection at Faro International Airport}

The method chosen to collect data from senior tourists was self-administered questionnaires using paper-and-pencil, with the support of inquirers who clarified doubts and showed photographs depicting what was being asked (e.g. raised platform, type of benches, QR codes, NFC technology).

In April, August and September of 2018, inquiries were conducted randomly at Faro International Airport, mainly in waiting areas before departure. In April, they were conducted by a tourist student and in the other months by professional inquirers.

A convenience sampling method was used in which the participants were randomly selected. Senior tourists from diverse geographical contexts were approached and asked to participate in the study. After their acceptance, a printed version of the inquiry was given to them.

\subsubsection{Sampling Procedure}

The purpose of sampling in this project was to make comparisons across age groups of senior tourists of 60-64 years old, 65-69, 70-74, 75-79, 80-84, 85-89 years old and older than or equal to 90 , as well as senior tourists with functional diversity, such as with or without disabilities that affect their mobility.

The number of elderly tourists visiting Portugal using Faro Airport is high, according to data given by VINCI Airports/ANA Aeroportos de Portugal. In the summer of 2018, $7 \%$ of passengers were over 60 years old. In August of that year, 1,156,279 passengers were registered of whom 80,940 were elderly, and in September 1,090,104 passengers of whom 76,307 were elderly.

In this survey with a population size of 157,247 , for a $95 \%$ confidence level and approximately $3.4 \%$ degree of accuracy (percentage of maximum error required), a sample size of inquiries equal to 851 was achieved.

\subsubsection{Statistical analysis}

Data was introduced into an electronic file and advanced statistical analysis capabilities of Statistical Product and 
Service Solutions (SPSS) was used.

Descriptive statistics of the frequency of each answer were created, characterizing elderly tourists by gender, age and mobility capacity.

\subsection{Results}

\subsubsection{Characterization of elderly tourists}

The characterization of elderly tourists is made considering: gender, age, level of education, professional occupation, country of residence, city or town where they reside, disabilities affecting mobility, and need for technical aids to get around the town.

From valid inquiries, $60.6 \%$ are elderly men, $39.2 \%$ elderly women, $0.1 \%$ are "other" gender, and $0.6 \%$ did not respond. Older people predominate in the age group 60-69 (44.8\%), 7079 amounts to $39.9 \%$, and only $15.4 \%$ are aged 80 or over.

Concerning different levels of education, $2.5 \%$ have a basic level, 23.2\% have secondary level, 54.0\% have vocational/technical training, and $20.3 \%$ have higher level. Concerning their professional situation $70.3 \%$ are retired, $21.7 \%$ still work full time, and $4.3 \%$ work part-time.

The elderly tourists come from over thirty countries, but mainly from the United Kingdom (40.6\%), Germany (13.8\%), Ireland (8.6\%), France (7.8\%), Spain (3.8\%), Italy (3.3\%), and Belgium (3.2\%). These elderly people mostly live in a city (75.3\%).

As ageing is usually associated with dependency, loss of functionality, and cognitive impairment, older people were asked if they had disabilities that affected their mobility, and $25.2 \%$ answered positively. Disability varies according to gender and age group. Considering elderly female tourists $26.9 \%$ have at least one disability, and elderly male tourists $24.1 \%$. In general, disabilities increase with age: $7.9 \%$ of elderly people in the first age group (from 60 to 64 years old), and $68.5 \%$ in the last age group (85 or older).

The nature of the disability is mainly related to motor problems $(61.6 \%)$, hearing problems $(15.2 \%)$, visual problems $(14.8 \%)$, and orientation problems (1.7\%). Furthermore, $17.4 \%$ of older people use technical aids to get around, $31.3 \%$ specify cane, $16.2 \%$ crutches, $12.3 \%$ tripod/quadripod, and $12.3 \%$ wheelchair. Furthermore, $59.0 \%$ of older people have no limitations in using public transport, $14.1 \%$ have difficulty in walking, $13.4 \%$ difficulty in climbing steps or stairs, $3.3 \%$ have difficulty in staying upright, $3.3 \%$ have hearing problems, and $2.9 \%$ have visual problems.

Considering elderly people with disabilities, $70.0 \%$ need technical aids to move around town, namely: cane, tripod or quadripod stick, crutches, walking frame, wheelchair, mobility scooter and white cane.

Elderly tourists with disabilities come mainly from the United Kingdom (45.3\%), Germany (14.5\%), Ireland (9.8\%), Spain $(5.6 \%)$, France $(5.1 \%)$, and Belgium (3.3\%). These elderly people with disabilities mostly live in a city (78.8\%).

2.3.2 Perceptions of bus stop environments by senior tourists with and without disabilities

The participants were asked to specify their perception of the conditions for universal accessibility in bus stop environments, considering the surroundings of bus stops and the bus stops' elements, in their daily lives, in the country where they live.

Considering the perceptions of the attributes of the neighbouring environments of bus stops (Figure 1) the majority of inquired elderly tourists consider that there are universal accessibility attributes in their countries, in particular: "sidewalks have barrier-free space" (68.1\%), "there are no obstacles around the bus stop" (65.5\%), "around the bus shelters there is enough space to manoeuvre a wheelchair" (64.4\%), "sidewalks have non-slip pavement and regular surface" (63.8\%), "bus stops are well lit outside" (61.5\%), "pedestrian crossings are safe and convenient" $(61.2 \%)$, "there are ramps with gentle slopes and dropped/cut kerb" $(55.3 \%)$, and "sidewalks are lit and senior people feel safe" $(55.3 \%)$.

A minority affirm that "pedestrian crossings have ramps with tactile paving" $(43.9 \%)$, and "the ramps have a different colour to the sidewalks" (41.7\%).

Considering the opinions of senior citizens with disabilities that affect their mobility, they are much more critical of all attributes, possibly because they have more difficulties in travelling. Comparing senior citizens without disabilities, the criticism focuses mainly on "sidewalks are lit and they feel safe" (45.8\%), "there are ramps with gentle slopes and kerb cuts" $(46.3 \%)$, "bus stops are well lit outside" (53.7\%), and "sidewalks have non-slip pavement and regular surface" $(57.0 \%)$.

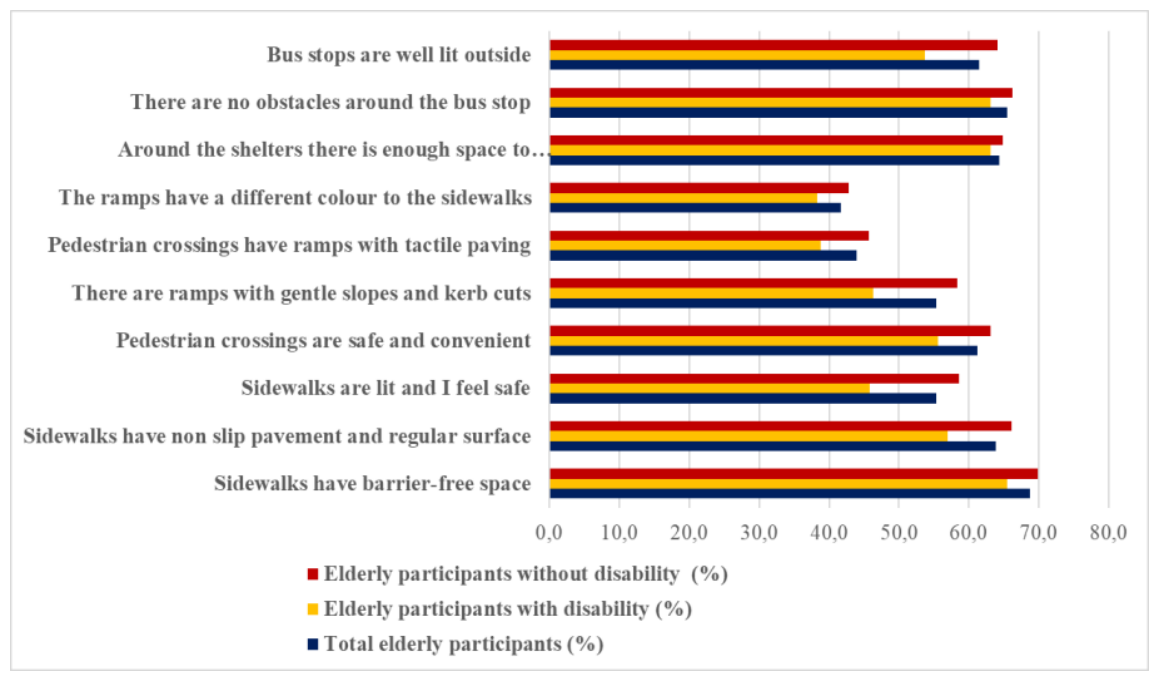

Figure 1. Perceptions of elderly tourists regarding the attributes of the neighbouring environment of a bus stop in their countries (Source: own elaboration) 


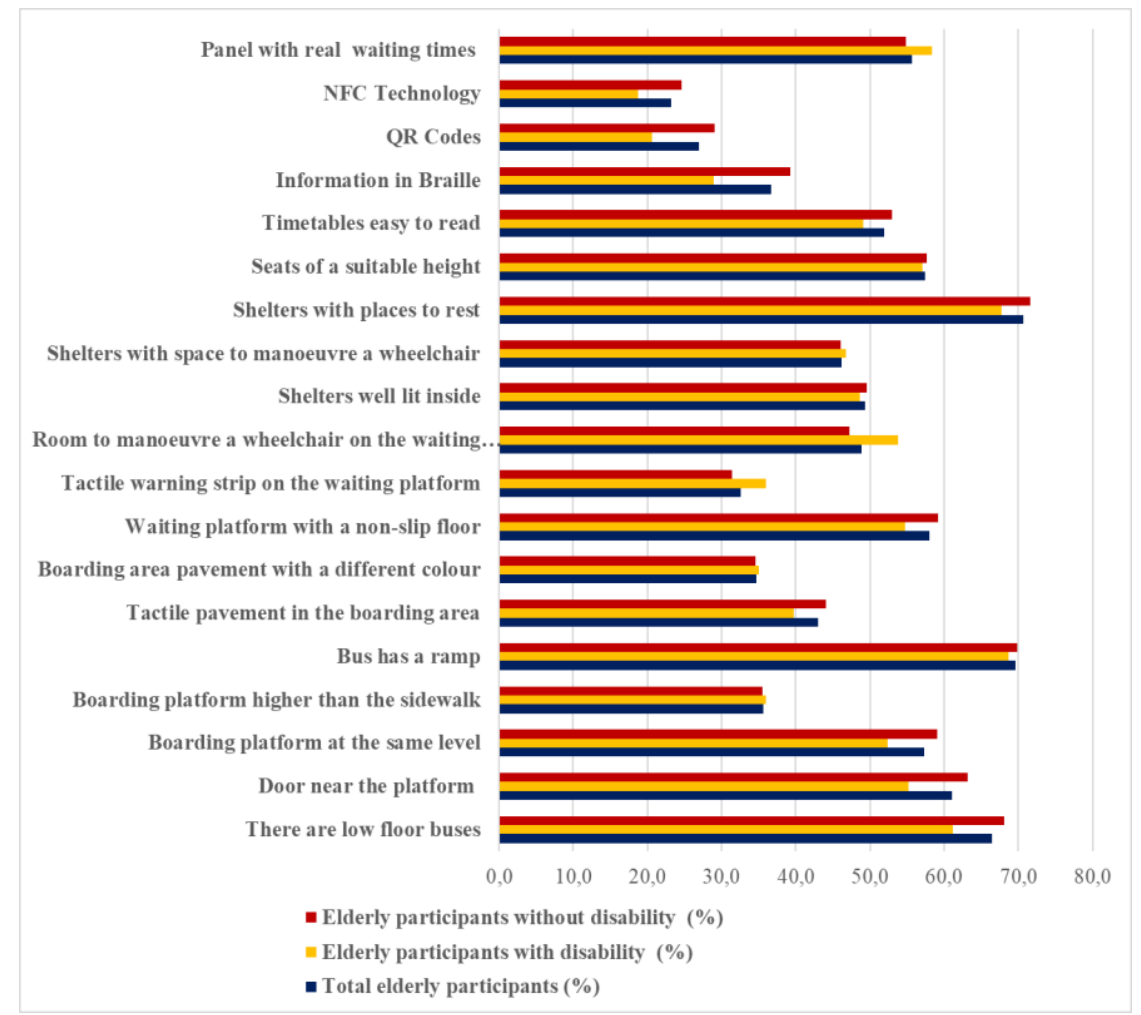

Figure 2. Perceptions of elderly tourists about the attributes of a bus stop in their countries (Source: own elaboration)

Considering the perceptions of inquired elderly tourists of the attributes of bus stop elements (Figure 2), these are not so assertive.

The majority of the inquired elderly tourists consider that there are some universal accessibility attributes in their countries, in particular: "shelters with places to rest" $(70.6 \%)$, "bus has a ramp" (69.6\%), "there are low floor buses" (66.4\%), "door near the platform" (61.1\%), "waiting platform with a non-slip floor" (58.0\%), "seats of a suitable height" (57.5\%), "boarding platform at the same level" (57.3\%), and "timetables easy to read" (51.9\%) .

A minority affirm that "shelters are well lit inside" (49.4\%), "there is room to manoeuvre a wheelchair on the waiting platform" (48.9\%), "shelters with space to manoeuvre a wheelchair" (46.2\%), "there is tactile pavement on the boarding area" (43.0\%), "there is information in Braille" (36.7\%), "boarding platform higher than the sidewalk" (35.6\%), "boarding area pavement with a different colour" (34.7\%), "tactile warning strip on the waiting platform" $(32.5 \%)$, "there are QR Codes" $(26.9 \%)$, and "there is NFC Technology" (23.1\%).

Considering the opinions of senior citizens with disabilities that affect their mobility, they are much more critical of specific attributes, possibly because they are more perceptive of them. Comparing senior citizens without disabilities, the criticism focuses mainly on "there is information in Braille" (29.0\%), "there are QR Codes" (20.6\%), "door near the platform" (55.1\%), "there are low floor buses" (61.2\%), "boarding platform at the same level" (52.3\%), and "there is NFC Technology" (18.7\%).

With regard to older tourists without disabilities, the percentage of senior tourists with disabilities who are aware of the following attributes increases: "panel with real waiting times" $(58.4 \%)$, "room to manoeuvre a wheelchair on the waiting platform" $(53.7 \%)$, and "tactile warning strip on the waiting platform" $(36.0 \%)$

\section{CONCLUSIONS}

Presently, there is the perception that all elements of the travel chain must be consistently accessible and easy to understand for a journey to be possible for everybody. Assessments of pedestrian and bus stop infrastructures that consider the quality of the urban design in the travel chain can be useful in establishing whether elements of the chain are erratic or poor.

Universal accessibility in bus stops considers urban aspects, specific pavements and surface materials, information and communication for all, and adapted urban fixtures.

This phase of ACCES4ALL Project is based on the viewpoints of individual people (i.e. each participant has brought in his/her point of view and experiences), and therefore the information obtained in this study has some acceptable subjectivity that can be taken into account in the collaborative design of the final layout of the bus stop.

Considering the perceptions of the attributes of the neighbouring environments of bus stops, inquired elderly tourists have strong perceptions about urban aspects of universal accessibility, obstacle free spaces, surfaces, safety in pedestrian crossings and lighting.

Considering the opinions of senior citizens with disabilities that affect their mobility, they are much more critical of all attributes, possibly because they have more difficulties in travelling.

There is a small perception about ramps with tactile paving and colour contrast, probably because not all countries consistently consider these surfaces.

When considering the perceptions of the attributes of bus stop elements by the inquired elderly tourists, these are not so assertive. They have more perceptions of seating and easy access to the vehicle and fewer perceptions of digital technologies. Considering the opinions of senior citizens with disabilities that affect their mobility, they have more 
perception of attributes concerning communication (panel with real waiting times), obstacle free spaces (room to manoeuvre a wheelchair on the waiting platform) and risk perception (tactile warning strip on the waiting platform).

There is some criticism around pedestrian crossings, bench design and the lack of room for wheelchair users.

Elderly tourists with disabilities come mainly from the United Kingdom, Germany, Ireland, Spain, France and Belgium, European countries known for their public policies on social inclusion which have been expressed in the built environment and for the implementation of digital solutions.

By asking different age groups of senior tourists, with different functional diversity, about their perceptions, this study conclude that some attributes of the universal accessibility of bus stop environments have been implemented in countries where senior tourists come from. The opinions of senior citizens with disabilities that affect their mobility are much more critical of many attributes, possibly because they have a greater perception of these attributes. Then, older people with disabilities should be involved in collaborative processes of designing the built environment.

Traditionally, in the design phase of bus stops, the professionals consider all people, regardless the age and disability. However, this is not that simple since some products and materials can be useful only for some people and not for others. An example of this is the use of tactile paving on bus stops. The utilization of these surfaces can be essential for some people with disabilities (e.g. people with visual impairments); though to some people it can be uncomfortable to walk on it. Hence it is essential to take into account all the people involved, to improve everyone's life, and try to reduce any undesirable impacts in these areas [12].

Future research will try to understand the use of tactile surfaces by different people.

Age-friendly bus stops [13] are an essential part of a sustainable public transport system in a tourist region with a senior tourism strategy.

\section{ACKNOWLEDGMENT}

The Project ACCES4ALL - Accessibility for All in Tourism (SAICT-POL/23700/2016) was sponsored by the Portuguese Science and Technology Foundation (FCT) and Portugal 2020, and co-funded by European Regional Development Fund (ERDF), through Regional Operational Programme of CRESC Algarve 2020 and Regional Operational Programme of Norte 2020.

\section{REFERENCES}

[1] Rosa, M.P., Gil, F. (2017). Design universal: A necessidade de uma abordagem transdisciplinar. Omnia Revista Interdisciplinar de Ciências e Artes, 6: 15-24. http://dx.doi.org/10.23882/OM06-2017-04-02

[2] Preiser, W.F.E., Ostroff, E. (2001). Universal Design Handbook. Mcgraw-Hill Professional, New York.

[3] Rosa, M.P., Landim, I., Loureiro, N.S. (2020). Cultural accessible pedestrian ways. The case of Faro historic centre. Journal of Tourism and Heritage Research, 3(2): 75-95. http://jthr.es/index.php/journal/article/view/162
[4] Kockelman, K., Heard, L., Kweon, Y.J., Rioux, T.W. (2002). Sidewalk cross-slope design: Analysis of accessibility for persons with disabilities. Transportation Research Board, 1818(1): 108-118. http://dx.doi.org/10.3141/1818-17

[5] Ferreira, M.A.G., Sanches, S.P. (2007). Proposal of a sidewalk accessibility index. Journal of Urban and Environmental Engineering, 1(1): 1-9. http://doi.org/10.4090/juee.2007.v1n1.001009

[6] TDM Encyclopedia. Transit oriented development: Using public transit to create more accessible and livable neighborhoods. Victoria Transport Policy Institute. https://www.vtpi.org/tdm/tdm45.htm, accessed on Sep. 10, 2019.

[7] Corazza, M.V., Favaretto, N. (2019). A methodology to evaluate accessibility to bus stops as a contribution to improve sustainability in urban mobility. Sustainability, 11(3): 803-825. http://dx.doi.org/10.3390/su11030803

[8] Shea, E.C.O., Pavia, S., Dyer, M., Craddock, M., Murphy, N. (2014). Measuring the design of empathetic buildings: A review of universal design evaluation methods. Disability and Rehabilitation: Assistive Technology, 11(1):

$13-21$. http://dx.doi.org/10.3109/17483107.2014.921842

[9] Aittoniemi, E., Kotiranta, P., Vatanen, M., Virtanen, A. (2008). Integrating existing service content into ASK-IT, accessibility information on bus and tram stops and departures on the Internet. 2nd ASK-IT International Conference, Nuernberg. https://cris.vtt.fi/en/publications/integrating-existingservice-content-into-ask-it-accessibility-in

[10] Caymaz, G.F.Y. (2018). Assessment of commuter satisfaction in the usage of bus-shelters: The Ataköy zone 5 and Beşyol metrobus stops, Istanbul. Architecture and Urban Planning, 14(1): 6-13. http://dx.doi.org/10.2478/aup-2018-0001

[11] United Nations (2017). World Population Ageing Highlights (ST/ESA/SER.A/397). Department of Economic and Social Affairs. https://www.un.org/en/development/desa/population/pu blications/pdf/ageing/WPA2017 Highlights.pdf, accessed on Jul. 23, 2019.

[12] Pinto, P.C., Assunção, H., Rosa, M.P. (2020). Senior tourists' perceptions of tactile paving at bus stops and in the surrounding environment: Lessons learned from project ACCES4ALL. International Journal of Sustainable Development and Planning, 15(4): 413-421. https://doi.org/10.18280/ijsdp.150401

[13] Rosa, M.P., Lopes, J.C. (2019). Senior tourists' perceptions of bus stop environments for collaborative design. WIT Transactions on the Built Environment, 186: 121-132. https://doi.org/10.2495/UT190111

\section{NOMENCLATURE}

e.g. For example

i.e. In other words

NFC Near Field Communication

QR Quick Response

SPSS Statistical Product and Service Solutions 